\title{
Zastosowanie TLC w ukladzie faz odwróconych oraz metod obliczeniowych do wyznaczenia lipofilowości eplerenonu
}

\author{
Małgorzata Dołowy'1, Katarzyna Syc², Karolina Raczek², Karolina Sośnierz², Alina Pyka-Pająk \\ ${ }^{1}$ Zakład Chemii Analitycznej, Wydział Farmaceutyczny z Oddziałem Medycyny Laboratoryjnej w Sosnowcu, \\ Śląski Uniwersytet Medyczny w Katowicach \\ ${ }^{2}$ Koło Naukowe działające przy Zakładzie Chemii Analitycznej, Wydział Farmaceutyczny z Oddziałem Medycyny Laboratoryjnej w Sosnowcu, \\ Śląski Uniwersytet Medyczny w Katowicach
}

Adres do korespondencji: Małgorzata Dołowy, Śląski Uniwersytet Medyczny w Katowicach, Zakład Chemii Analitycznej, Wydział Farmaceutyczny z Oddziałem Medycyny Laboratoryjnej SUM w Sosnowcu, ul. Jagiellońska 4, 41-200 Sosnowiec, e-mail: mdolowy@sum.edu.pl

\section{Wstęp}

Spośród wielu parametrów fizykochemicznych jednym z ważniejszych determinujących aktywność biologiczną związków chemicznych jest lipofilowość. Parametr ten często jest wykorzystywany w projektowaniu nowych leków do przewidywania nie tylko ich potencjalnego działania biologicznego, mechanizmu wiązania $\mathrm{z}$ receptorami, ale również do określenia ich biodostępności i toksyczności [1]. Miarą lipofilowości danej cząsteczki związku chemicznego jest wartość P lub logP, czyli współczynnik podziału lub odpowiednio jego logarytm, który wyrażany jest jako stosunek stężenia danej substancji odpowiednio w fazie organicznej $\left(\mathrm{C}_{0}\right)$ i w fazie wodnej $\left(\mathrm{C}_{\mathrm{w}}\right)$ w stanie równowagi:

$$
P=\frac{C_{0}}{C_{w}}
$$

Najczęściej stosowanym parametrem lipofilowości jest współczynnik podziału wyznaczony metodą ekstrakcji ciecz-ciecz (shake-flask method) w układzie n-oktanol/woda, który jest najbliższy układowi faz polarnych i niepolarnych występujących w ustroju biologicznym. Ze względu na dużą pracochłonność i małą precyzję klasycznej ekstrakcji jest ona zastępowana przez chromatografię cieczową w układzie faz odwróconych, tj. RP-TLC/ RP-HPTLC lub odpowiednio RP-HPLC. Chromatograficzny parametr lipofilowości wyznaczony techniką chromatografii cienkowarstwowej lub odpowiednio wysokosprawnej chromatografii cieczowej posłużył do oceny lipofilowości, a następnie aktywności biologicznej wielu nowo zsyntezowanych związków organicznych [2-6]. W praktyce, w celu dokonania krytycznej oceny uzyskanych wyników, często dokonuje się porównania danych doświadczalnych otrzymanych różnymi technikami, w tym chromatograficznymi, z wartościami współczynnika podziału $(\log \mathrm{P})$ wyznaczonymi teoretycznie, tj. obliczonymi przy użyciu różnych programów komputerowych, czyli tzw. metody in silico. Eksperymenty in silico wykonywane przy użyciu różnych algorytmów obliczeniowych coraz częściej stosowane są w badaniach nad nowymi lekami $[7,8]$. Pozwalają one już w początkowych etapach projektowania nowych cząsteczek jako potencjalnych kandydatów nowych leków wyznaczyć różne deskryptory fizykochemiczne, w tym lipofilowość, które warunkują nie tylko określoną aktywność biologiczną tych nowych związków, ale również ich właściwości toksyczne i potencjalne działania niepożądane.

W niniejszej pracy, w celu określenia lipofilowości eplerenonu, zastosowano technikę chromatografii cienkowarstwowej w układzie faz odwróconych (RP-TLC i RP-HPTLC) oraz metody obliczeniowe, tj. ogólnie dostępny w internecie zestaw oprogramowania do przewidywania właściwości fizykochemicznych, w tym lipofilowości związków chemicznych na podstawie ich struktury chemicznej, autorstwa doktora Igora Tetko [9].

Eplerenon to steroid, pochodna spironolaktonu o działaniu diuretycznym, który jest 
przedstawicielem nowej klasy leków zalecanych pacjentom po zawale serca $\mathrm{z}$ cechami niewydolności lewej komory [10-14]. Ten syntetyczny steroid jest antagonistą receptora mineralokortykoidowego. W przeciwieństwie do spironolaktonu wykazuje większą specyficzność do powyższego receptora. Dlatego obserwuje się znacznie mniej przypadków działań niepożądanych podczas jego stosowania, takich jak: ginekomastia u mężczyzn czy obfite krwawienie $\mathrm{z}$ dróg rodnych u kobiet, w porównaniu $\mathrm{z}$ innymi lekami [10-14].

Ze względu na brak danych literaturowych dotyczących doświadczalnej wartości parametru lipofilowości eplerenonu, w niniejszej pracy zastosowano technikę chromatografii cienkowarstwowej RP-TLC/RP-HPTLC i różne układy chromatograficzne do wyznaczenia eksperymentalnej wartości parametru lipofilowości tego związku. Uzyskane dane porównano z teoretycznymi wartościami $\log \mathrm{P}$ uzyskanymi za pomocą różnych algorytmów obliczeniowych.

\section{Materialy i metody}

Przedmiotem badań był metanolowy roztwór eplerenonu (Sigma-Aldrich, $298 \%$ ). Metanol, dioksan i aceton do HPLC (POCh, Gliwice, Polska) oraz wodę zastosowano jako składniki faz ruchomych. Wykorzystano różne płytki chromatograficzne, tj. do RP-TLC pokryte żelem krzemionkowym RP$-18 \mathrm{~F}_{254}$ oraz odpowiednio do RP-HPTLC pokryte żelem krzemionkowym RP-18 $\mathrm{WF}_{254} \mathrm{i} \mathrm{RP}-2 \mathrm{~F}_{254}$ (E. Merck, Niemcy), o wymiarach $5 \mathrm{~cm} \times 10 \mathrm{~cm}$. Komora chromatograficzna $20 \mathrm{~cm} \times 10 \mathrm{~cm}(\mathrm{Ca}-$ mag, Szwajcaria) służyła do rozwijania stosowanych w badaniach płytek chromatograficznych.

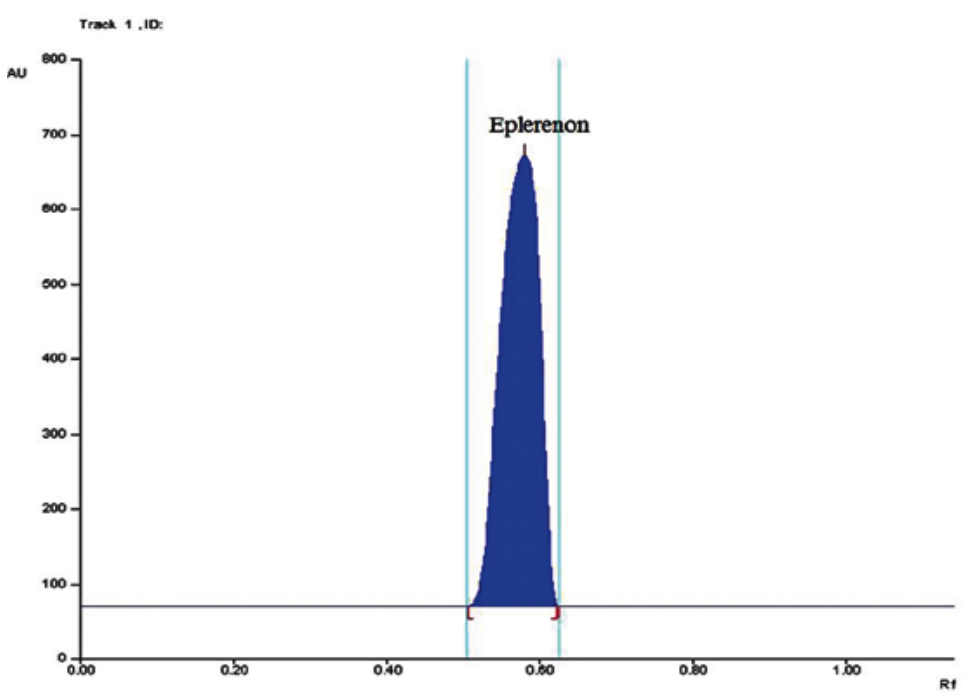

Rycina 1. Densytogram eplerenonu otrzymany na płytkach chromatograficznych $\mathrm{RP}-18 \mathrm{~F}_{254}$ przy użyciu fazy ruchomej metanol-woda
Natomiast densytometr TLC 3 (Camag, Szwajcaria) z oprogramowaniem winCATS 1.4.2 oraz lampa deuterowa jako źródło promieniowania wykorzystano w pomiarach densytometrycznych wartości współczynnika opóźnienia $\left(\mathrm{R}_{\mathrm{F}}\right)$ analizowanego związku.

\section{Wyznaczenie chromatograficznego parametru lipofilowości eplerenonu techniką RP-TLC i RP-HPTLC}

Analizę lipofilowości badanego eplerenonu przeprowadzono, stosując jego metanolowy roztwór o stężeniu $1 \mathrm{mg} / \mathrm{ml}$. Roztwór ten nanoszono każdorazowo na płytki chromatograficzne w ilości $3 \mathrm{mi}-$ krolitrów. Płytki rozwijano przy użyciu następujących faz ruchomych: metanol-woda, dioksan-woda $i$ aceton-woda. Objętość stosowanej fazy ruchomej wynosiła $50 \mathrm{ml}$. Zawartość modyfikatora organicznego w fazie ruchomej, czyli odpowiednio metanolu, dioksanu i acetonu, zmieniała się co 5\% objętościowych w zakresie od 50 do 100\% (v/v). Po wysuszeniu przez 24 godz., plytki poddawano skanowaniu densytometrycznemu, przy optymalnej dtugości fali $\lambda=246 \mathrm{~nm}$. Na rycinie 1 przedstawiono przykładowy densytogram eplerenonu, uzyskany na płytce pokrytej żelem krzemionkowym $\mathrm{RP}-18 \mathrm{~F}_{254}$, która była rozwijana przy użyciu fazy ruchomej metanol-woda.

Uzyskane na drodze skanowania densytometrycznego chromatogramów eplerenonu (otrzymanych techniką RP-TLC i RP-HPTLC) wartości współczynnika opóźnienia we wszystkich zastosowanych ukladach chromatograficznych posłużyły do obliczenia wartość $\mathrm{R}_{\mathrm{M}}$ dla eplerenonu, zgodnie z poniższym wzorem:

$$
\mathrm{R}_{\mathrm{M}}=\log \left(\frac{1}{\mathrm{R}_{\mathrm{F}}}-1\right)
$$

Ekstrapolacja liniowa otrzymanych wartości $\mathrm{R}_{\mathrm{M}}$ do zerowego stężenia modyfikatora organicznego w fazie ruchomej będąca konsekwencją zastosowania w kolejnym etapie równania Soczewińskiego-Wachtmeistera (3) pozwoliła na uzyskanie wartości parametru lipofilowości wyrażonej jako $\mathrm{R}_{\mathrm{MW}}$, zgodnie $\mathrm{z}$ poniższym równaniem regresji liniowej:

$$
\mathrm{R}_{\mathrm{M}}=\mathrm{R}_{\mathrm{MW}}-\mathrm{S} \cdot \varphi
$$

gdzie:

$\varphi$ - ułamek objętościowy organicznego składnika, tj. metanolu, dioksanu lub odpowiednio acetonu w eluencie;

S - nachylenie krzywej regresji. 


\section{Wyznaczenie teoretycznych wartości wspólczynnika podzialu $(\log \mathrm{P})$ eplerenonu}

Źródłem teoretycznych wartości współczynnika podziału w postaci $\log \mathrm{P}$ dla analizowanego eplerenonu, które zostały wyznaczone przy użyciu różnych algorytmów obliczeniowych, takich jak: AlogPs, AClogP, milogP, AlogP, MlogP, xlogP3, xlogP2 oraz średniej wartości $\log \mathrm{P}\left(\log \mathrm{P}_{\text {sred }}\right)$, była internetowa baza danych Virtual Computational Chemistry Laboratory [9].

\section{Wyniki}

W tabeli 1 zestawiono teoretyczne wartości współczynnika podziału w postaci jego logarytmu, czyli $\log \mathrm{P}$, oraz wartość średnią $\left(\log \mathrm{P}_{\text {sted }}\right)$. Natomiast w tabeli 2 przedstawiono parametry równań liniowej ekstrapolacji wartości $R_{M}$ do zerowego stężenia modyfikatora organicznego w eluencie, czyli metanolu, dioksanu i acetonu, uzyskane przy użyciu różnych płytek chromatograficznych, tj. RP- $18 \mathrm{WF}_{254}$, $\mathrm{RP}-18 \mathrm{~F}_{254}$ i RP- $2 \mathrm{~F}_{254}$, w tym współczynnik kierunkowy uzyskanych liniowych zależności (S) oraz wyraz wolny, stanowiący wartość chromatograficznego parametru lipofilowości $\left(\mathrm{R}_{\mathrm{MW}}\right)$ badanego eplerenonu. $\mathrm{W}$ tabeli 2 zamieszczono również współczynniki korelacji liniowej (r) dla każdego z zaprezentowanych równań, uzyskane w oparciu o liczbę pomiarów (n) oraz błąd standardowy dla wszystkich estymacji (s) i wartość F.

Porównanie eksperymentalnych wartości parametru lipofilowości $\left(\mathrm{R}_{\mathrm{MW}}\right)$ wyznaczonych dla eplerenonu techniką RP-TLC oraz RP-HPTLC w różnych układach chromatograficznych z teoretycznymi
Tabela 1. Współczynnik podziału (logP) uzyskany za pomocą różnych algorytmów obliczeniowych (Virtual Computational Chemistry Laboratory, stan z dnia 10 stycznia 2018r.) [9]

\begin{tabular}{|c|c|}
\hline Wspólezynnik podzialu & Wartość liczbowa wspólezynnilka podzialu \\
\hline $\log P_{\text {exp }}$ & - \\
\hline AlogPs & 1,67 \\
\hline AlogP & 2,02 \\
\hline AClogP & 1,85 \\
\hline milogP & 1,74 \\
\hline MlogP & 3,03 \\
\hline$x \log P 2$ & 1,28 \\
\hline$x \log P 3$ & 1,39 \\
\hline logPśred & $1,85( \pm 0,58)$ \\
\hline
\end{tabular}

wartościami współczynnika podziału w postaci logP zaprezentowano na rycinie 2.

Rycina 3 przedstawia dendrogram podobieństwa wartości chromatograficznych parametrów lipofilowości $\left(\mathrm{R}_{\mathrm{MW}}\right)$ uzyskanych w trzech układach chromatograficznych: metanol-woda $(\mathrm{m})$, aceton-woda (a) oraz dioksan-woda (d) z użyciem płytek RP-18WF ${ }_{254}, \mathrm{RP}-18 \mathrm{~F}_{254}$ i RP- $2 \mathrm{~F}_{254}$.

\section{Omówienie wyników}

Głównym celem pracy było wyznaczenie eksperymentalnej wartości parametru lipofilowości eplerenonu przy użyciu chromatografii cienkowarstwowej w układzie faz odwróconych, tj. RP-TLC i odpowiednio RP-HPTLC w różnych warunkach chromatograficznych, a następnie porównanie uzyskanych danych z teoretycznymi wartościami współczynnika podziału, tj. logP, uzyskanymi za pomocą metod obliczeniowych. Badany eplerenon,

Tabela 2. Wartości chromatograficznego parametru lipofilowości eplerenonu $\left(\mathrm{R}_{\mathrm{MW}}\right)$ wyznaczone techniką TLC w układzie faz odwróconych (RP-TLC i RP-HPTLC)

\begin{tabular}{|c|c|c|c|c|c|c|c|}
\hline \multicolumn{8}{|c|}{ Parametry liniowej korelacji $R_{M}=R_{M w}-S \times \varphi^{*}$} \\
\hline Badany związek & Phytki chromatograficzne & $R_{\mathrm{wm}}( \pm \mathrm{SD})$ & $S( \pm S D)$ & r & s & $F$ & n \\
\hline \multirow[t]{12}{*}{ Eplerenon } & \multicolumn{7}{|c|}{ metanol-woda (v/v) } \\
\hline & $\mathrm{RP}-18 \mathrm{WF}_{254}$ & $0,63( \pm 0,04)$ & $1,14( \pm 0,05)$ & 0,999 & 0,011 & 533,3 & 6 \\
\hline & $\mathrm{RP}-18 \mathrm{~F}_{254}$ & $3,11( \pm 0,58)$ & $4,11( \pm 0,68)$ & 0,974 & 0,151 & 37,0 & 7 \\
\hline & $\mathrm{RP}-2 \mathrm{~F}_{254}$ & $1,55( \pm 0,16)$ & $2,58( \pm 0,19)$ & 0,994 & 0,043 & 180,9 & 6 \\
\hline & \multicolumn{7}{|c|}{ aceton-woda (v/v) } \\
\hline & $\mathrm{RP}-18 \mathrm{WF}_{254}$ & $2,62( \pm 0,46)$ & $4,35( \pm 0,60)$ & 0,964 & 0,252 & 52,2 & 6 \\
\hline & $\mathrm{RP}-18 \mathrm{~F}_{254}$ & $1,92( \pm 0,19)$ & $2,92( \pm 0,25)$ & 0,986 & 0,104 & 138,8 & 6 \\
\hline & $\mathrm{RP}-2 \mathrm{~F}_{254}$ & $2,35( \pm 0,59)$ & $3,94( \pm 0,76)$ & 0,933 & 0,319 & 26,7 & 6 \\
\hline & \multicolumn{7}{|c|}{ dioksan-woda (v/v) } \\
\hline & $\mathrm{RP}-18 \mathrm{WF}_{254}$ & $1,37( \pm 0,16)$ & $2,52( \pm 0,21)$ & 0,993 & 0,046 & 148,4 & 6 \\
\hline & $\mathrm{RP}-18 \mathrm{~F}_{254}$ & $1,73( \pm 0,07)$ & $2,94( \pm 0,08)$ & 0,999 & 0,026 & 1271,1 & 7 \\
\hline & $\mathrm{RP}-2 \mathrm{~F}_{254}$ & $2,20( \pm 0,31)$ & $3,83( \pm 0,40)$ & 0,989 & 0,117 & 93,5 & 6 \\
\hline
\end{tabular}

gdzie: * - $p<0,001, S D$ - odchylenie standardowe 


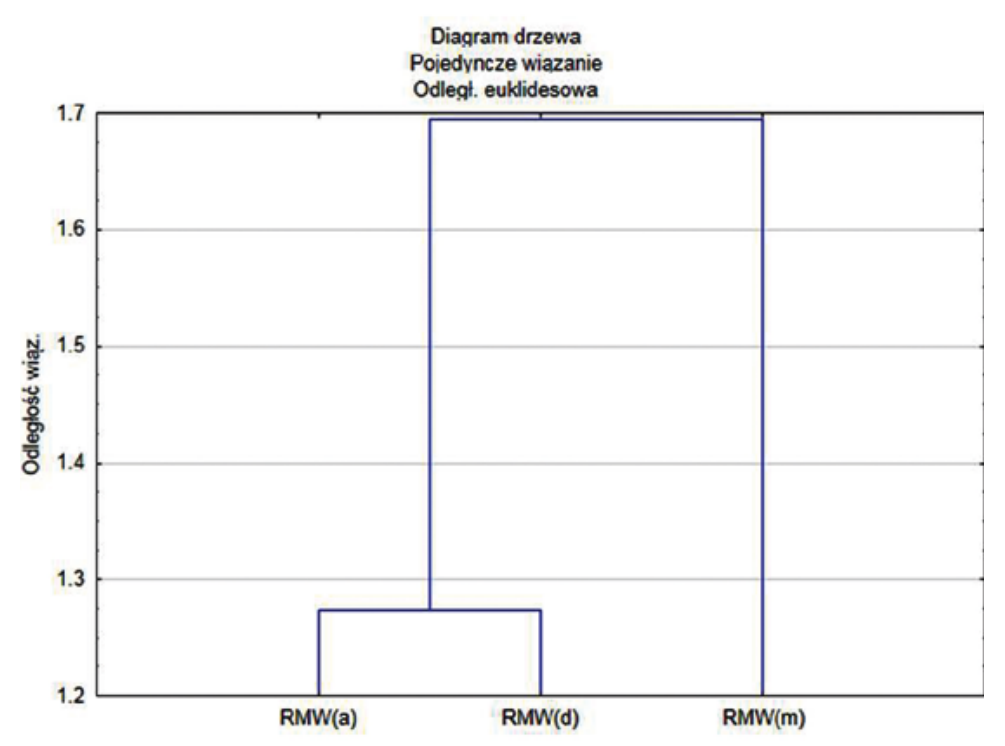

Rycina 2. Dendrogram podobieństwa wartości $\mathrm{R}_{\mathrm{MW}}$ uzyskanych w trzech układach chromatograficznych: metanol-woda (m), dioksan-woda (d) oraz aceton-woda (a)

podobnie jak spironolakton, to syntetyczny steroid z grupy antagonistów aldosteronu stosowany w leczeniu nadciśnienia tętniczego i niewydolności serca. W poprzedniej pracy wykazano przydatność techniki TLC, jak również HPLC do wyznaczenia lipofilowości spironolaktonu [15]. Kontynuując powyższe badania, w niniejszej pracy postanowiono dokonać oceny przydatności chromatografii cienkowarstwowej do określenia lipofilowości innego (nowego) steroidu z grupy antagonistów receptorów aldosteronowych, mianowicie eplerenonu.
W literaturze brak jest eksperymentalnej wartości współczynnika podziału eplerenonu wyznaczonego metodą ekstrakcji w układzie n-oktanol/woda lub za pomocą innych technik analitycznych, w tym chromatografii cienkowarstwowej, który mógtby być miarą jego lipofilowości.

Analiza teoretycznych wartości współczynnika podziału (tabela 1) dostępnych w postaci logP, które zostały oszacowane za pomocą różnych algorytmów obliczeniowych (AlogPs, AlogP, AClogP, mi$\log \mathrm{P}, \mathrm{M} \log \mathrm{P}, \mathrm{x} \log \mathrm{P} 2, \mathrm{x} \log \mathrm{P} 3)$, wskazuje na różną siłę predykcji programów komputerowych, jeśli chodzi o przewidywanie wartość logP jako istotnego parametru lipofilowości. Uzyskana za pomocą programów obliczeniowych wartość liczbowa współczynnika podziału dla eplerenonu mieści się w zakresie 1,28-3,03, co daje wartość średnią wynoszącą dla eplerenonu $1,85 \pm 0,58$. Najmniejszą wartość obserwuje się w przypadku xlogP2 $(1,28)$, a największą dla MlogP $(3,03)$.

Najbardziej zbliżone do siebie wyniki $\log \mathrm{P}$ uzyskuje się dla eplerenonu w przypadku AlogPs $(1,67)$ oraz milogP $(1,74)$, a także dla xlogP2 $(1,28)$ i odpowiednio xlogP3 $(1,39)$.

Wartości chromatograficznego parametru lipofilowości $\left(\mathrm{R}_{\mathrm{MW}}\right)$ wyznaczone techniką RP-TLC i RP-HPTLC w różnych warunkach chromatograficzych, zestawione w tabeli 2, wskazują również na pewne zróżnicowanie w wartościach tego parametru lipofilowości. Najniższą wartość, równą 0,63 , obserwuje się dla płytek pokrytych żelem krzemionkowym RP-18 $\mathrm{WF}_{254}$ i fazy ruchomej metanol-woda. $\mathrm{Z}$ kolei najwyższą wartość $\mathrm{R}_{\mathrm{MW}}$, tj. 3,11, uzyskano
Rycina 3. Porównanie teoretycznych oraz wyznaczonych eksperymentalnie, tj. techniką RP-TLC i RP-HPTLC, parametrów lipofilowości eplerenonu

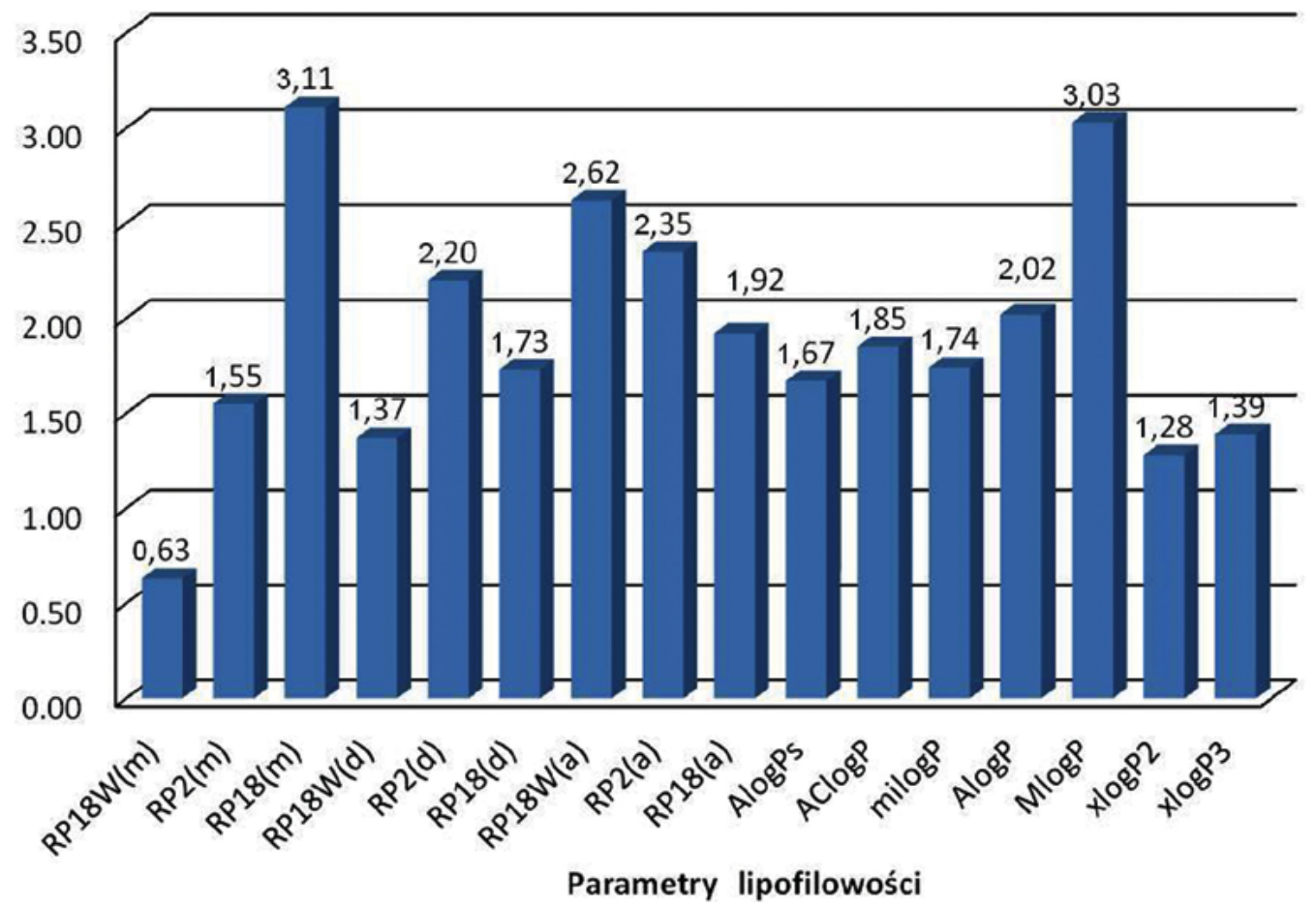


stosując tę samą fazę ruchomą i płytki chromatograficzne $\mathrm{RP}-18 \mathrm{~F}_{254}$. Średnia wartość chromatograficznego parametru lipofilowości obliczona na podstawie wszystkich uzyskanych wyników $\mathrm{R}_{\mathrm{Mw}}$ wynosi 1,94 $\pm 0,73$, co oznacza, że jest ona zbliżona do średniej wartości współczynnika podziału (logP) dla badanego eplerenonu otrzymanego metodami obliczeniowymi.

Dalsza analiza wyników chromatograficznego parametru lipofilowości otrzymanych przy użyciu wszystkich trzech faz ruchomych oraz plytek chromatograficznych (tabela 2) wskazuje na duże podobieństwo pomiędzy wartościami $\mathrm{R}_{\mathrm{MW}}$ otrzymanymi w następujących warunkach chromatograficznych:

- na płytkach $\mathrm{RP}-2 \mathrm{~F}_{254}$ dla fazy ruchomej dioksan-woda (RP2(d)) oraz przy użyciu mieszaniny aceton-woda (RP2(a));

- na plytkach $\mathrm{RP}-2 \mathrm{~F}_{254}$ dla fazy ruchomej metanol-woda (RP2(m)) i RP-18F ${ }_{254}$ analizowanych za pomocą fazy ruchomej dioksan-woda (RP18(d));

na plytkach $\mathrm{RP}-18 \mathrm{~F}_{254}$ badanych za pomocą fazy ruchomej dioksan-woda (RP18(d)) i odpowiednio aceton-woda (RP18(a)).

na płytkach $\mathrm{RP}-18 \mathrm{WF}_{254}$ analizowanych przy użyciu fazy ruchomej dioksan-woda (RP18W(d)) oraz $\mathrm{RP}-2 \mathrm{~F}_{254}$ rozwijanych za pomocą mieszaniny metanol-woda (RP2(m)).

Dendrogram podobieństwa wartości $\mathrm{R}_{\mathrm{MW}}$ na rycinie 2 wskazuje na to, że spośród trzech przebadanych faz ruchomych największe podobieństwo wykazują do siebie wartości chromatograficznego parametru lipofilowości otrzymane przy użyciu fazy ruchomej dioksan- woda RMW(d) i aceton-woda, tj. RMW(a), co tłumaczy zbliżona polarność dioksanu i acetonu, stanowiących składniki tych dwóch faz ruchomych.

Zestawienie wszystkich, tj. teoretycznych i chromatograficznych, parametrów lipofilowości na rycinie 3 świadczy o tym, że najbardziej zbliżone do siebie teoretyczne i eksperymentalne (tj. chromatograficzne) parametry lipofilowości, to:

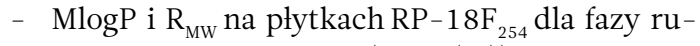
chomej metanol-woda (RP18(m)),

- $\quad x \log$ P3 oraz $\mathrm{R}_{\mathrm{MW}}$ na ptytkach RP-18WF ${ }_{254}$ dla fazy ruchomej dioksan-woda (RP18W(d)),

- AlogP i $\mathrm{R}_{\mathrm{MW}}$ na płytkach RP-2 $\mathrm{F}_{254}$ dla fazy ruchomej dioksan-woda (RP2(d)),

- AlogPs i $\mathrm{R}_{\mathrm{MW}}$ na płytkach RP- $18 \mathrm{~F}_{254}$ dla fazy ruchomej dioksan-woda ((RP18(d)).

Z kolei porównanie zarówno teoretycznych, jak i eksperymentalnych wartości chromatograficznego parametru lipofilowości uzyskanych dla eplerenonu z danymi otrzymanymi dla spironolaktonu wskazuje na to, że spironolakton wykazuje większą lipofilowość wyrażoną w postaci $\log \mathrm{P}_{\text {sred }}=2,78$ oraz odpowiednio za pomocą $\mathrm{R}_{\mathrm{MW}}=2,88-3,77$, uzyskanych techniką RP-TLC i RP-HPTLC dla tych samych warunków chromatograficznych, co badany eplerenon [15].

Zaprezentowane $\mathrm{w}$ niniejszej pracy wartości eksperymentalnego parametru lipofilowości $\left(\mathrm{R}_{\mathrm{MW}}\right)$ wskazują na przydatność techniki TLC w układzie faz odwróconych jako techniki alternatywnej w odniesieniu do klasycznej ekstrakcji do wyznaczania lipofilowości eplerononu. Wyniki te mogą być przydatne $\mathrm{w}$ przyszłości $\mathrm{w}$ badaniach farmakokinetyki eplerenonu lub jego analogów.

\section{Wnioski}

Na podstawie uzyskanych wyników stwierdzono, że chromatografia cienkowarstwowa w ukladzie faz odwróconych, tj. RP-TLC i RP-HPTLC, jest przydatnym narzędziem w przewidywaniu rzeczywistej wartości parametru lipofilowości eplerono$\mathrm{nu}$, steroidu o działaniu diuretycznym stosowanego w leczeniu nadciśnienia tętniczego i niewydolności serca. Wyznaczona techniką TLC, na podstawie analizy chromatograficznej eplerenonu przeprowadzonej w różnych układach chromatograficznych, średnia wartość chromatograficznego parametru lipofilowości $\left(\mathrm{R}_{\mathrm{MW}}\right)$ jest zbliżona do średniej teoretycznej wartości współczynnika podziału $(\log \mathrm{P})$ wyznaczonej metodami obliczeniowymi. Oznacza to, że technika TLC może być z powodzeniem stosowana jako alternatywna do klasycznej ekstrakcji w układzie n-oktanol/woda w badaniach lipofilowości steroidów z grupy diuretyków, do których należy obok spironolaktonu analizowany w poniższej pracy eplerenon.

\section{Podziękowania}

Badania zostaty sfinansowane przez Śląski Uniwersytet Medyczny $w$ Katowicach. Projekt nr KNW-1-019/K/6/O oraz KNW-1-013/K/7/O.

Otrzymano: 2018.02.06 - Zaakceptowano: 2018.02.15

\section{Piśmiennictwo}

1. Rutkowska E., Pająk K., Jóźwiak K.: Lipophilicity-methods of determination and its role in medicinal chemistry. Acta Pol. Pharm.- Drug Res. 2013, 70(1): 3-18.

2. Paneth A., Hawrył A, Plech T., Hawrył M., Świeboda R., Janowska D, Wujec M., Paneth P.: Lipophilicity studies on thiosemicarbazide derivatives. Molecules, 2017, 22(6): 952

3. Flieger J., Czajkowska-Żelazko A., Rządkowska M., Szacoń E., Matosiuk D.: Usefulness of reversed-phase HPLC enriched with room temperature imidazolium based ionic liquids for lipophilicity determination of the newly synthesized analgesic active urea derivatives. J. Pharm. Biomed. Anal. 2012, 66: 58-67.

4. Fijałkowski Ł., Nowaczyk A.: Zależność między strukturą a aktywnością w grupie związków o działaniu przeciwgrzybicznym. Farm. Pol. 2016, 72(6): 406-415.

5. Rudraraju A.V., Amoyaw P.N., Hubin T.J., Khan M.O.: Determination of $\log$ P values of new cyclen based antimalarial drug leads using RP-HPLC. Pharmazie, 2014, 69(9): 655-662. 
6. Bajda M., Bucki A., Szlek J., Szwaczkiewicz M., Świerczek M., Malawska B.: Determination of lipophilicity of alpha-(4-phenylpiperazine) derivatives of $\mathrm{N}$-benzylamides using chromatographic and computational methods. Biomed. Chromatogr. 2008, 22(4): 428-432.

7. Polak S., Wiśniowska B.: Modelowanie komputerowe w badaniach nad lekiem - projektowanie i poszukiwanie cząstki aktywnej, ocena właściwości fizykochemicznych oraz aktywności biologicznej. Farm. Pol. 2009, 65(3): 214-223

8. Wiśniowska B., Polak S. Modelowanie komputerowe w badaniach nad lekiem - przewidywanie potencjalnych działań toksycznych. Farm. Pol. 2009, 65(6): 445-452.

9. Tetko I.V., Tanchuk V.J.: VCC n Lab. Interactive analysis logP prediction [Internet] http://www.vcclab.org/lab/alogps [dane z dnia 10 stycznia 2018].

10. Brennan B. J., Martin N. E.: Eplerenone: selective aldosterone antagonism in management of cardiovascular and renal disease. J. Am. Pharm. Assoc. 2004, 44(5): 604-611.
11. Watanabe M., Krum H.: Eplerenone for the treatment of cardiovascular disorders. Expert Rev. Cardiovasc. Ther. 2012, 10(7): 831-838.

12. Colussi G., Catena C., Sechi L.A.: Spironolactone, eplerenone and the new aldosterone blockers in endocrine and primary hypertension. J. Hypertens. 2013, 31(1): 3-15.

13. Trzaska E., Gumułka W., Makulska-Nowak H. E.: Antagoniści aldosteronu w farmakoterapii chorób układu krążenia. Kardiol. Pol. 2009, 67: 667-671.

14. Brown N.J.: Eplerenone: cardiovascular protection. Circulation, 2003, 107(19): 2512-2518.

15. Dołowy M., Pyka A.: Lipophilicity assessment of spironolactone by means of reversed phase liquid chromatography and by newly developed calculation procedures. Acta Pol. Pharm.-Drug. Res. 2015, $72(2): 235-244$. 